III. Aus dem hygienischen Institut der Universität Königsberg i. Pr.

\title{
Ueber die immunisirende Wirkung mit Choleraamboceptoren beladener Cholera-
} vibrionen.

\section{Von R. Pfeiffer.}

(Schluss aus No. 50.)

Ferner war der schwerwiegende Einwand möglich, dass eine Absüttigung der Choleravibrionen mit Amboceptoren der Ziege vielleicht nur einen Theil der Affinitäten dieses complizirten Gebildes für die Rezeptoren des Kaninchens sättigt, während andere frei bleiben und zur Produktion von Schutzstoffen anregen könnten.

Nach diesen Erwägungen mussten wir erwarten, dass die Verwendung des Serums choleraimmuner Kaninchen in unseren Ver* 
suchen die Entstehung der Choleraantikörper entweder ganz verhindern oder doch in auffallender Weise verringern würde. Das Resultat entsprach nicht diesen Voraussetzungen.

Bei der theoretischen Wichtigkeit dieser Experimente wird deren genaue Beschreibung nicht unwesentlich erscheinen. Eine geringe Menge 12-18stündiger Choleraagarkultur (in der Regel 1 Oese) wurde mit $0,05 \mathrm{~cm}^{3}$ hochwirksamen Serums choleraimmuner Kaninchen (Titer $1 / 5$, resp. $1 / 2 \mathrm{mg}$ ) versetzt und gleich darauf einem Meerschweinchen ins Peritoneum injizirt.

Diese Serumdosis stellt das mindestens 200 fache Multiplum derjenigen Serummenge dar, welche zur Auflösung der einen Oese Cholera ausgereicht hätte, sodass ein sehr hoher Ueberschuss von Choleraantikörper verwendet wurde.

Eine Stunde nach der Injektion wurde nun das Meerschweinchen, in dessen Bauchhöhle unter Kügelchenbildung die bekannte rapide Auflösung der Vibrionen stattgefunden hatte, durch Nackenschlag getödtet.
Sofort danach wurden etwa $6-10 \mathrm{~cm}^{3}$ auf $37^{0}$ erwärmter physiologischer Kochsalzlösung in die Bauchhöhle des Kadavers injizirt um damit den Inhalt des Peritoneums auszuwaschen. Die dann aus dem Peritoneum wiedergewonnene getrübte Flüssigkeit wurde jetzt durch ein Berkefeldfilter filtrirt und so von allen corpuskulären Elementen, auch von den Zerfallsprodukten der Vibrionen, soweit diese noch nicht vollständig gelöst waren, befreit. Es resultirte eine absolut klare Flüssigkeit, deren Sterilität durch Einsaat in Bouillon und auf Agar jedesmal festgestellt wurde.

Sofort nach der Filtration wurde die Flüssigkeit einem Kaninchen in die Ohrvene injizirt. Vor dieser Injektion und acht Tage nach der Vorbehandlung wurde dann dem Kaninchen Blut entnommen und auf seinen Gehalt an Choleraschutzstoffen geprüft. Drei hierher gehörige Versuche sind in Tabelle III wiedergegeben.

Tabelle III.

Intravenöse Injektion des filtrirten Peritonealexsudats von Meerschweinchen, in deren Banchhơle zıvor Choleravibrionen durch wirksames Serum von mit Cholera immunisirten Kaninchen zur Auflösung gebracht worden waren.

\begin{tabular}{|c|c|c|c|c|c|}
\hline $\begin{array}{l}\text { Injektionsdosis } \\
\text { intravenös }\end{array}$ & $\begin{array}{c}\text { Gewicht des } \\
\text { Kaninchens } \\
\text { in } g\end{array}$ & $\begin{array}{c}\text { Titer seines } \\
\text { Serums vor } \\
\text { Injektion }\end{array}$ & $\begin{array}{c}\text { Tag der } \\
\text { Titerprüfung } \\
\text { nach Injek- } \\
\text { tion }\end{array}$ & $\begin{array}{l}\text { Titer nach } \\
\text { Injektion }\end{array}$ & Bemerkungen. \\
\hline $\begin{array}{l}\text { Filtrirtes Peritonealexsn- } \\
\text { dat eines Meerschwein- } \\
\text { chens nach der Auflơsung } \\
\text { von Choleravibrionen in }\end{array}$ & 1650 & $\begin{array}{c}0,2 \\
\text { schützt } \\
\text { nicht. }\end{array}$ & VIII. & $\begin{array}{l}\text { zwischen } \\
0,0004 \\
\text { und } \\
0,0005\end{array}$ & $\begin{array}{l}\text { Das Meerschweinchen hatte } 1 \text { Stunde vor der Entnahme des } \\
\text { Peritonealexsudats intraperitoneal erhalten: } \\
\text { 1 Oese Cholera, } \\
\text { 0,01 wirksamen Kaninchenserums. }\end{array}$ \\
\hline & 2400 & do. & VI. & $\begin{array}{l}\text { zwischen } \\
0,01 \\
\text { und } \\
0,05\end{array}$ & $\begin{array}{l}\text { Das Meerschweinchen hatte } 1 \text { Stunde vor der Entnahme des } \\
\text { Peritonealexsudats intraperitoneal erhalten: } \\
1 \text { Oese Cholera. } \\
\text { 0,05 wirksamen Kaninchenserums. } \\
\text { Bei der intravenösen Injektion des filtrirten Banchhöhleninhalts } \\
\text { beim Kaninchen gerieth ein Theil in das Subkutangewebe. }\end{array}$ \\
\hline do. & 1860 & do. & VII. & $\begin{array}{l}\text { zwischen } \\
0,001 \\
\text { und } \\
0,002\end{array}$ & $\begin{array}{l}\text { Das Meerschweinchen hatte } 1 \text { Stinnde vor der Entnahme des } \\
\text { Peritonealexsudats erhalten: } \\
1 \text { Oese Cholera. } \dagger \\
0,05 \text { wirksamen Kaninchenserums. }\end{array}$ \\
\hline
\end{tabular}

Vorstehende Tabelle ergiebt zu folgenden Bemerkungen Veranlassung. Auch bei dieser Versuchsanordnung acquirirten sämmtliche Thiere einen sehr hohen Grad aktiver Immunität. Besonders gilt dies von Kaninchen No. I, wo der Titer des Serums den beträchtlichen Werth von etwa $1 / 3 \mathrm{mg}$ erreichte. Nur im Versuch II war eine relativ geringe Wirkung der Injektion zu verspüren, was mindestens zum Theil darauf zurückzuführen sein dürfte, dass hier die intravenöse Injektion nicht glatt gelang, sodass ein nicht unbeträchtlicher Antheil der zu injizirenden Flüssigkeit in das subkutane Gewebe eindrang.

Da es sich in diesen Versuchen um die Wirkung von gelösten Cholerasubstanzen handelt, die eben nur dann in gelöste Form übergehen konnten, wenn nicht allein die Amboceptoren, sondern auch die Complemente in das Bakterienmolekül verankert waren, so stehen wir hier vor einer gewissen Schwierigkeit, den thatsächlich beobachteten sehr starken immunisirenden Effekt auf Grund der Ehrlich'schen Theorie ohne allzu gezwungene Voraussetzung zu erklären.
In einer früheren Arbeit haben wir bewiesen, dass das normale Blut der Ziege Substanzen enthält, welche durch Cholerabakterien ausgefällt werden können, während sie beispielsweise durch Typhusbazillen nicht gebunden werden.

Es war damals die Frage offen gelassen worden, ob diese Amboceptoren des normalen Serums mit den spezifischen bei der Immunisirung auftretenden identisch seien, wie es Ehrlich annimmt, oder ob es sich um eine Mehrheit von den spezifischen Immunkörpern analogen Substanzen handelt.

Die oben erwähnten Untersuchungen legten uns den Gedanken nahe, zu prüfen, wie der immunisirende Effekt von Cholerabakterien, welche die Amboceptoren des normalen Ziegenserums verankert haben, sich verhalten würde.

Wir verwendeten das in unserer früheren Arbeit (diese Wochenschrift 1901, No. 48) beschriebene normale Ziegenserum III, dessen Titer gegenüber Cholera zwischen 0,05 bis 0,01 gelegen war.

Die genaue Versuchsanordnung ist aus der folgenden Tabelle zu ersehen.

Tabelle IV.

Intravenöse Injektion kleiner Dosen todter Choleravibrionen nach Absättigung mit Normalziegenserum.

\begin{tabular}{|c|c|c|c|c|c|c|c|}
\hline Dosis der Cholera & Dosis des Serums & $\begin{array}{l}\text { Behandlung des Cholera-Cholera } \\
\text { serumgemisches bis zur Injektion }\end{array}$ & $\begin{array}{l}\text { Gewicht } \\
\text { des } \\
\text { Thieres } \\
\text { in } \mathrm{g}\end{array}$ & $\begin{array}{l}\text { Titer vor } \\
\text { der } \\
\text { Injektion }\end{array}$ & $\mid \begin{array}{c}\text { Tag der } \\
\text { Titer- } \\
\text { prüfung nach } \\
\text { der Injektion }\end{array}$ & $\begin{array}{l}\text { Titer nach } \\
\text { der } \\
\text { Injektion }\end{array}$ & $\begin{array}{l}\text { Aggluti- } \\
\text { nations- } \\
\text { werth }\end{array}$ \\
\hline $\begin{array}{l}1 / 20 \text { Oese Cholera bei } \\
60^{\circ} \text { abgetodtet }\end{array}$ & $\begin{array}{l}0,5 \text { normales Zie- } \\
\text { genserum }\end{array}$ & $\begin{array}{l}\text { Die Mischung bleibt 24 Stunden bei } \\
\text { Zimmertemperatur stehen und wird } \\
\text { Kaninchen intravenös injizirt }\end{array}$ & 1200 & $\begin{array}{l}0,2 \text { schützt } \\
\text { nicht }\end{array}$ & VII & $\begin{array}{l}\text { zwischen } \\
0,005 \text { und } \\
0,001\end{array}$ & $1: 20$ \\
\hline $\begin{array}{l}1 / 10 \text { Oese Cholera bei } \\
60^{\circ} \text { abgetödtet }\end{array}$ & $\begin{array}{l}\text { 0,9 normales Zie- } \\
\text { genserum }\end{array}$ & do. & 1650 & do. & $\mathrm{X}$ & $\begin{array}{l}\text { zwischen } \\
0,001 \text { und } \\
0,005\end{array}$ & $1: 20$ \\
\hline
\end{tabular}


Auch hier fanden wir wieder das Resultat, dass kleine Mengen von abgetödteten Choleravibrionen, die 12 Stunden lang mit einem mindestens 10-20fachen Multiplum der zu ihrer Auflösung im Meerschweinchenperitonelım nöthigen Dosis normalen Ziegenserums in Contakt waren, ihre inmunisirende Wirkung in hohem Grade bewahrt haben. Besonders demonstrirt dies der Versuch II, wo der erzeugte Titer fast ebenso hoch war, wie er bei Controllthieren nach entsprechenden Dosen abgetödteter Cholerakiltıren ohne Serumsatz erreicht wird.

Es war also festzustellen, dass die Wirkung des normalen Ziegenserums und der darin enthaltenen, auf Cholerabakterien wirkenden Amboceptoren sich ähnlich wie die der Amboceptoren des Immunserums verhielt, nur war sie vielleicht quantitativ schwächer. Also auch auf diesem Wege liess sich eine sichere Differenzirung dieser beiden Amboceptorengruppen nicht erreichen. Im übrigen hätte man das Resultat dieser Versuche voraussehen können. Bei jeder Immunisirung mit lebenden oder todten Bakterien müssen die Bakteriensıbstanzen erst gelöst werden, ehe sie ihre Wirkıng entfalten können und sonach mit Amboceptor und Complement in Verbindung treten.

Meine Versuche mit der Immunisirung von Ziegen gegen Cholera und Typhus aus den Jahren 1895-97 haben ferner bewiesen, dass es möglich ist, allch bei Thieren, deren Blut enorme Mengen der spezifischen Amboceptoren enthält, durch fortgesetzte Injektion von Bakterien eine fortschreitende Produktion der spezifischen Schutzstoffe zu erzeugen. In diesen Experimenten wurden die injizirten lebenden oder todten Cholera-, resp. Typhısbakterien im subkutanen Gewebe gelöst und gelangten mit Amboceptor und Complement gesättigt in die Blıtbahn, um dann hier noch einen geradezu enormen Ueberschuss von Amboceptoren anzutreffen.

Allerdings könnte man gegen diese Ausführungen folgenden Einwand erheben: Die Bindung der im Blute kreisenden Amboceptoren mit den Vibrionenstoffen braucht nicht sofort ihre volle Festigkeit zu erreichen, sodass eine Dissoziirung im Contakt mit den Rezeptoren der möglicherweise empfänglicheren Körperzellen wohl möglich sein könnte.

In den Experimenten der Tabelle III dürfte das allerdings kaum zutreffen, da von dem Moment der Injektion des VibrionenCholeraserumgemisches in das Meerschweinchenbanchfell bis zur Injektion des filtrirten Exsudates in die Ohrvene des Kaninchens doch in ninimo drei Stunden verfliessen mussten, sodass wohl Zeit genug vorhanden war, um eine feste Verbindung der Vibrionen mit ihren zugehörigen, in enormem Ueberschuss vorhandenen Amboceptoren herbeizuführen. Ferner haben wir absichtlich in einzelnen hier nicht aufgefiihrten Versuchen derartige Exsudatfiltrate, welche noch einen erheblichen Ueberschuss von Choleraantikörpern enthielten, bis zu 24 Stunden bei Zimmertemperatur aufbewahrt, ehe wir sie in die Ohrvene von Kaninchen injizirten, und auch hierbei die gleichen hohen Titrewerthe erhalten.

In vollem Gegensatz zu den bisher berichteten Resultaten stehen die folgenden Versuchsergebnisse: Wir besäten flache, mit Bouillon etwa $1 \mathrm{~cm}$ hoch gefüllte Kölbchen mit Cholerabakterien und filtrirten die drei Tage im Brutschrank gewachsene Cholerabouillon durch Berkefeldfilter. Das vollkommen klare, auf Sterilität geprüfte Filtrat erzeugte bei einem Controllkaninchen in Dosis von $5 \mathrm{~cm}^{3}$ bei subkntaner Einverleibung einen enorm hohen Schutzwerth des Blutes. (Titer linter $0,001 \mathrm{~g}$; Agglutinationswerth $1: 100$ ). Von demselben Filtrat wurden je $5 \mathrm{~cm}^{3}$ mit je $1 / 2 \mathrm{~cm}^{3}$ Ziegencholeraserum (Titer $1 / 8 \mathrm{mg}$ ) versetzt und auf Eis gestellt. Nach 25 Stunden wurde das Gemisch, in dem sich ein ziemlich starker lockerer Niederschlag von ca. $2 \mathrm{~cm}$ Höhe gebildet hat (Präzipitinwirkung), zwei Kaninchen an vier Stellen subkutan injizirt. Das nach acht Tagen entnommene Blut zeigte sich in dem Versuch A in einer Dosis von 0,05 ganz unwirksam (leider wurden höhere Dosen nicht geprüft); im Versuch B war ein deutlicher, jedoch immerhin auffällig geringer Werth, einem Titer von 0,01 entsprechend zu finden. Agglutination fehlte.

Da diese Experimente mit unseren frïheren so wenig harmonirten, wurden sie auf breiter Basis nochmals wiederholt. Fïnf Kaninchen erhielten Cholerafiltrate mit Ziegencholeraserum, welches Gemisch verschieden lange Zeit gestanden hatte, die fünf Controllkaninchen, um die Experimente möglichst conform zu gestalten, dieselben Dosen des gleichen Cholerafiltrates, das aber mit entsprechenden Mengen Typhus-Ziegenserum versetzt war.

Tabelle V.

Subkutane Injektion dreitägiger steriler Filtrate von Cholerabouillonkulturen bei Kaninchen.

A. Ohne Serumzusatz.

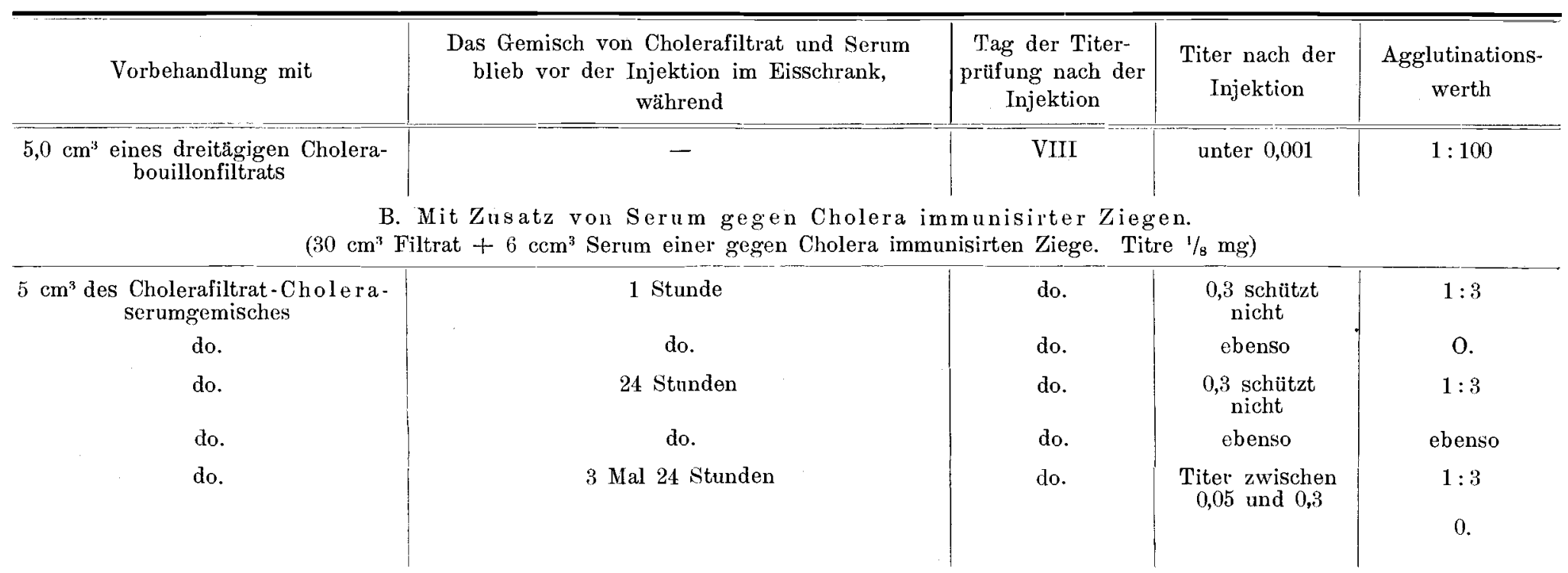

C. Mit Zusatz von Serumgegen Typhus immunisirter Ziegen.

(30 $\mathrm{cm}^{3}$ Cholerafiltrat $+6 \mathrm{~cm}^{3}$ Serum einer gegen Typhus immunisirten Ziege.)

\begin{tabular}{c}
\hline $\mathrm{cm}^{3}$ des Cholerafiltrat-Ty phus - \\
serum, gemischtes \\
do. \\
do. \\
do. \\
do.
\end{tabular}

\begin{abstract}
1 Stunde
do.
\end{abstract}

24 Stunden

do.

3 mal 24 Stunden do.

do.

do. 
Aus obiger Tabelle geht mit Sicherheit hervor, dass das Cho. leraserum die Cholerabonillonfiltrate vollständig unwirksam zu machen in Stande ist und dass schon nach einer Stunde Contakt der imınınisirende Effekt geschwınden ist, während das Typhusziegenserum, welches selbstverständlich hier nur die Wirkung eines normalen Ziegenserums entfalten konnte, die immunisirende Kraft des Filtrates nicht vernichtete, wenn auch offenbar erheblich beschränkte.

Wir sehen also hier einen dentlichen Unterschied zwischen Choleraimmınserım der Ziege ind normalem Ziegenserum. Doch würde es gewagt sein, daraus ohne weiteres anf eine Differenz der entsprechenden Amboceptoren zll schliessen, da die Menge des Filtrates recht erheblich war und möglicherweise das an Amboceptoren arme normale Ziegenserum zur Sättigung nicht ausreichte.

Es werden diese Versuche mit erheblich kleineren an der Grenze der Wirknng stehenden Filtratdosen zı wiederholen sein, worüber wir s. Z. berichten werden.

Es ist nun interessant, dass nach den Arbeiten von Behring, Ransom, Roux, Metschnik of und Salimbeni derartige Cholerafiltrate, in welchen nicht mehr die intakten Vibrionenstoffe enthalten sind, sondern deren durch die Wirkung ihrer eigenen Fermente abgebauten und dadurch wasserlöslich gewordenen Derivate sich auch bei der Immunisirung ganz anders verhalten als die lebenden oder schonend abgetödteten Vibrionensubstanzen.

Während letztere ausschliesslich bakteriolytische Körper erzeugen, regen erstere daneben anch die Bildnng antitoxisch wirkender Antikörper an. Hervorzuheben ist, dass das von mir hier verwendete Choleraziegenserum, welches ausschliesslich durch lebende Vibrionen erzeugt worden war, trotz alledem den immunisirenden Effekt der Cholerafiltrate aufzuheben vermochte. Offenbar liegen hier so verwickelte Verhältnisse vor, dass zur Zeit eine befriedigende Erklärung noch nicht gegeben werden kann. 